OPEN ACCESS

Edited by:

Tao Chen,

Tianjin University, China

Reviewed by:

Zheng-Jun Li,

Beijing University of Chemical

Technology, China

Guang Zhao,

Shandong University, China Jiong Hong,

University of Science and Technology

of China, China

*Correspondence: Jingen $L i$

lijg@tib.cas.cn

Chaoguang Tian

tian_cg@tib.cas.cn

Specialty section:

This article was submitted to

Synthetic Biology,

a section of the journal

Frontiers in Bioengineering and

Biotechnology

Received: 23 November 2021

Accepted: 14 December 2021

Published: 19 January 2022

Citation:

Gu S, Zhao Z, Yao Y, Li J and Tian C (2022) Designing and Constructing a Novel Artificial Pathway for Malonic Acid Production Biologically.

Front. Bioeng. Biotechnol. 9:820507. doi: 10.3389/fbioe.2021.820507

\section{Designing and Constructing a Novel Artificial Pathway for Malonic Acid Production Biologically}

\author{
Shuying $\mathrm{Gu}^{1,2,3}$, Zhen Zhao ${ }^{1,2,3}$, Yonghong Yao ${ }^{1,2}$, Jingen $\mathrm{Li}^{1,2 *}$ and Chaoguang Tian $^{1,2 *}$ \\ ${ }^{1}$ Key Laboratory of Systems Microbial Biotechnology, Tianjin Institute of Industrial Biotechnology, Chinese Academy of Sciences, \\ Tianjin, China, ${ }^{2}$ National Technology Innovation Center of Synthetic Biology, Tianjin, China, ${ }^{3}$ University of Chinese Academy of \\ Sciences, Beijing, China
}

Malonic acid is used as a common component of many products and processes in the pharmaceutical and cosmetic industries. Here, we designed a novel artificial synthetic pathway of malonic acid, in which oxaloacetate, an intermediate of cytoplasmic reductive tricarboxylic acid (rTCA) pathway, is converted to malonic semialdehyde and then to malonic acid, sequentially catalyzed by a-keto decarboxylase and malonic semialdehyde dehydrogenase. After the systematic screening, we discovered the enzyme oxaloacetate decarboxylase Mdc, catalyzing the first step of the artificially designed pathway in vitro. Then, this synthetic pathway was functionally constructed in cellulolytic thermophilic fungus Myceliophthora thermophila. After enhancement of glucose uptake, the titer of malonic acid achieved $42.5 \mathrm{mg} / \mathrm{L}$. This study presents a novel biological pathway for producing malonic acid from renewable resources in the future.

\begin{abstract}
Keywords: malonic acid, a-keto decarboxylase, oxaloacetic acid, metabolic engineering, Myceliophthora thermophila
\end{abstract}

\section{INTRODUCTION}

Malonic acid, formally known as propanedioic acid, is widely used in manufacturing processes, such as the petrochemical, pharmaceutical, and cosmetic industries. Traditionally, malonic acid is produced from fossil resources via petrochemical processes. The byproduct sodium cyanide is dangerous and unfriendly to the environment (Hildbrand and Pollak, 2012; Werpy et al., 2004; Klikar et al., 2017). With increasing concerns on energy and environmental problems, the production of malonic acid by microbial fermentation via bioconversion of renewable feedstock has generated considerable interest worldwide. However, due to a lack of knowledge about the malonic acid synthesis pathway, there is little progress on the biological production of malonic acid.

Recent advances in synthetic biology and computational biology have enabled designing novel and specific metabolic pathways for desired chemicals (Atsumi et al., 2008). However, importing and overexpressing non-native pathways in microbes may lead to metabolic imbalance, resulting in none or low titer of target products. It is critical to design artificial synthetic pathways that are compatible with the host. At present, two non-natural metabolic pathways have been sought and introduced into microbes, using malonic semialdehyde (MSA) or malonyl-CoA as the precursor (Table 1) (Song et al., 2016; Dietrich et al., 2017; Chae et al., 2020). The first one uses MSA from the deamination reaction of $\beta$-alanine as the precursor. In Escherichia coli, $\beta$-alanine pyruvate transaminase from Pseudomonas aeruginosa was overexpressed to convert $\beta$-alanine to produce MSA. Then, succinate semialdehyde dehydrogenase encoded by E. coli yneI was used to catalyze the reaction of MSA to malic acid, and the titer of malonic acid reached $3.60 \mathrm{~g} / \mathrm{L}$ by fed-batch fermentation (Song et al., 2016). Another pathway is dependent 
TABLE 1 | Summary of microbial production of malonic acid from glucose.

\begin{tabular}{|c|c|c|c|c|c|}
\hline Microbe & Precursor & Description & Titer & Fermentation & Refs \\
\hline Escherichia coli & $\beta$-Alanine & $\begin{array}{l}+p p c, \text { aspA, and ynel from E. coli; +panD from Corynebacterium glutamicum; } \\
+p a 4123 \text { from Pseudomonas aeruginosa; } \Delta y d f G\end{array}$ & $\begin{array}{l}0.45 \mathrm{~g} / \mathrm{L} \\
3.6 \mathrm{~g} / \mathrm{L}\end{array}$ & $\begin{array}{l}\text { Fed batch } \\
\text { Shake flask }\end{array}$ & $\begin{array}{l}\text { Song et al. } \\
(2016)\end{array}$ \\
\hline E. coli & Acyl-CoA & +ehd3 mutant from Saccharomyces cerevisiae & $82.3 \mathrm{mg} / \mathrm{L}$ & Shake flask & $\begin{array}{l}\text { Dietrich et al. } \\
\text { (2017) }\end{array}$ \\
\hline Pichia kudriavzevii & Acyl-CoA & +ehd3 mutant from S. cerevisiae; +Anmae1 from Aspergillus niger & 76 mg/L & Shake flask & $\begin{array}{l}\text { Dietrich et al. } \\
\text { (2017) }\end{array}$ \\
\hline $\begin{array}{l}\text { Myceliophthora } \\
\text { thermophila }\end{array}$ & Oxaloacetate & $\begin{array}{l}+ \text { mdc from Ogataea parapolymorpha; +ynel from E. coli; +glt-1 from } \\
\text { Neurospora crassa }\end{array}$ & $42.5 \mathrm{mg} / \mathrm{L}$ & Shake flask & This study \\
\hline
\end{tabular}

Note. "+" represents overexpression of target gene; " $\Delta$ " represents disruption of target gene.

on the fatty acid synthesis pathway, using malonyl-CoA as the precursor. Matthew et al. reported that acyl-CoA hydrolase encoded by ehd3 from Saccharomyces cerevisiae can hydrolyze malonyl-CoA to malonic acid. During overexpression of EHD3 in S. cerevisiae, Pichia kudriavzevii, and E. coli, malonic acid in the cultures was detectable. After improvement of binding affinity of acyl-CoA hydrolase to malonyl-CoA by protein engineering, production of malonic acid was increased to $0.0823 \mathrm{~g} / \mathrm{L}$ by engineered E. coli (Dietrich et al., 2017). Both current synthetic pathways of malonic acid require a number of enzymes to convert glucose to target acid and are complex, which might lead to a low titer of malonic acid. So more research is needed to improve the production of this dicarboxylic acid, including novel biosynthetic pathway design, key enzymatic engineering, and even alternative hosts.

Filamentous fungi are classical predominant microorganisms for organic acid production, such as citric acid, malic acid, and lactic acid (Dave and Punekar, 2015; Kirimura et al., 2016; Li et al., 2020a). The thermophilic filamentous fungus Myceliophthora thermophila (synonym: Thermothelomyces thermophilus), possessing the ability to efficiently degrade plant biomass, represents a potential library of new industrial applications, including producing thermo-tolerant and efficient cellulolytic enzymes and synthesizing biochemicals and biofuels directly from plant biomass (Berka et al., 2011; Yang et al., 2015; Singh, 2016). M. thermophila has been employed to synthesize bio-based products, such as malic acid, fumaric acid, and bioethanol, through metabolic engineering using CRISPR/ CAS9 system (Liu et al., 2017; Gu et al., 2018; Li et al., 2020a; Li et al., 2020b). In this study, we designed a novel synthetic pathway of malonic acid and screened the key enzyme, oxaloacetate decarboxylase, in vitro. In this pathway, oxaloacetic acid (OAA) can be converted to MSA and then to malonic acid and sequentially catalyzed by $a$-keto decarboxylase and MSA dehydrogenase. Moreover, this artificial synthetic pathway was functionally constructed in M. thermophila to produce malonic acid from glucose.

\section{MATERIALS AND METHODS}

\section{Strains and Culture Conditions}

M. thermophila ATCC 42464 was obtained from the American Type Culture Collection (ATCC). The wild-type strain and its mutants were grown on Vogel's minimal medium supplemented with $2 \%$ glucose (MM medium) at $35^{\circ} \mathrm{C}$ for approximately 12 days to obtain mature conidia, and antibiotics were added when needed for transformant screening.

E. coli DH5a and E. coli BL21 (DE3) were cultivated in Luria-Bertani medium supplemented with $100 \mu \mathrm{g} / \mathrm{ml}$ of ampicillin for plasmid selection.

\section{Vector Construction}

For overexpressing target genes in E. coli, the codon-optimized genes encoding oxaloacetate decarboxylase and MSA dehydrogenase were synthesized by GENEWIZ (Suzhou, China) and inserted between NdeI and XhoI of the plasmid pET-21a(+).

For the construction of plasmids overexpressing target genes in $M$. thermophila, codon-optimized mdc (XP_013934857.1) from Ogataea parapolymorpha, under control of the strong constitutive promoter of $\mathrm{Pap}$ amplified from the plasmid pPk2, was inserted between the BglII and BamHI sites of pAN52-PtrpC-Bar-PMtgpdA to generate the vector pAN52-Pap-mdc, using the NEB Gibson Assembly Kit. Similarly, the PCR fragments of the strong constitutive promoter of pgk (MYCTH_2316240) from M. thermophila and the opening reading fragment of $y n e I$ from $E$. coli were inserted between the BglII and BamHI sites of pAN52-PtrpC-bar-PMtgpdA to generate the plasmid pAN52-PtrpC-bar-PMtpgk-yneI. Under control of the strong constitutive promoter of $p g k$ (MYCTH_2316240) of $M$. thermophila, Anmae1 encoding the C4-dicarboxylate transporter from Aspergillus niger were inserted between the BglII and BamHI sites of pAN52-PtrpC-neo-PMtpgk to form the vector pAN52PtrpC-neo-PMtpgk-Anmae1. The PCR fragments of glucose transporter-encoding genes glt-1 from Neurospora crassa were inserted between the Spe1 and BamHI sites of pAN52-PtrpC-barPMtgpdA to generate the plasmid pAN52-PtrpC-bar-PMtgpdAAnmae1.

All vectors were constructed using E. coli DH5a. The target genes cloned into shuttle vectors were sequenced to verify the authenticity of the plasmid construction. All the primers used for plasmid construction are listed in Supplementary Table S1.

\section{Recombinant Proteins Expression and Purification}

E. coli BL21 (DE3) strains harboring expression plasmids were grown at $37^{\circ} \mathrm{C}$ in $100 \mathrm{ml}$ of LB media supplemented with $100 \mu \mathrm{g} /$ 
$\mathrm{ml}$ of ampicillin to an optical density $\mathrm{OD}_{600}$ of $0.4-0.5$. Then, $0.4 \mathrm{mM}$ of isopropyl- $\beta$-D-thiogalactopyranoside (IPTG) was supplemented, and the cells were cultivated at $16^{\circ} \mathrm{C}$ for $19 \mathrm{~h}$. Cells were harvested by centrifugation at $4^{\circ} \mathrm{C}$, resuspended in $50 \mathrm{mM}$ of Tris- $\mathrm{HCl}$ ( $\mathrm{pH} 7.5$ ) buffer, and crushed with an ultrasound crusher. After centrifugation, the supernatant was collected and loaded onto a $\mathrm{Ni}^{2+}$-NTA-agarose column preequilibrated with binding buffer $(50 \mathrm{mM}$ of TAE (Tris-acetateEDTA) buffer, $300 \mathrm{mM}$ of $\mathrm{NaCl}$, and $20 \mathrm{mM}$ of imidazole, $\mathrm{pH}$ 7.5). The retained proteins were recovered with elution buffer (20 mM of $\mathrm{Na}_{2} \mathrm{HPO}_{4}-\mathrm{NaH}_{2} \mathrm{PO}_{4}, \mathrm{pH} 7.4,500 \mathrm{mM}$ of $\mathrm{NaCl}$, and $500 \mathrm{mM}$ of imidazole). In order to eliminate salt and imidazole, the eluted fraction was filtered by an ultrafiltration centrifugal tube. The purified protein is stored at $-20^{\circ} \mathrm{C}$. The purity of the enzymes was analyzed by sodium dodecyl sulfate-polyacrylamide gel electrophoresis (SDS-PAGE), and protein concentration in supernatants was measured using a Bio-Rad protein assay kit based on absorbance at $590 \mathrm{~nm}$, using bovine serum albumin as the standard.

\section{In Vitro Enzyme Reaction}

To synthesize malonic acid from OAA in vitro, the reaction mixture $(2 \mathrm{ml})$ containing $50 \mathrm{mM}$ (pH 7.5) of Tris- $\mathrm{HCl}, 1 \mathrm{mM}$ of $\mathrm{NAD}^{+}, 1 \mathrm{mM}$ of $\mathrm{MgSO}_{4}, 1 \mathrm{mM}$ of thiamine pyrophosphate (TPP), excessive purified YneI (approximately $40 \mu \mathrm{l}$ ), and $100 \mu \mathrm{l}$ of purified Mdc was used. The assay was started by the addition of $1 \mathrm{mM}$ of OAA and was immediately monitored at $340 \mathrm{~nm}$ for $5 \mathrm{~min}$. Subsequently, the reactants were analyzed by gas chromatography/mass spectrometry (GC/MS).

\section{Gas Chromatography-Mass Spectrometry Assay}

Samples (reaction products and malonic acid standard) were dried using a CentriVap vacuum concentrator. Then, the dried samples were dissolved in $20 \mu \mathrm{l}$ of pyridine solution containing $20 \mathrm{mg} / \mathrm{ml}$ of methoxyamine hydrochloride and incubated for $90 \mathrm{~min}$ at $30^{\circ} \mathrm{C}$. After that, $50 \mu \mathrm{l}$ of the MSTFA reagent (containing $1 \%$ TMCS, v/v) was added to the sample aliquots, mixed well, and then incubated for $1 \mathrm{~h}$ at $37^{\circ} \mathrm{C}$. The mixture was assayed by GC/MS as described previously (Mao et al., 2021).

\section{Analytical Method of Sugar}

Residual glucose in the culture was determined by highperformance liquid chromatography (HPLC) equipped with a Waters (Milford, MA, USA) 2414 refractive index detector and an Aminex HPX-87H column (Bio-Rad Laboratories, Hercules, CA, USA) at $35^{\circ} \mathrm{C} . \mathrm{H}_{2} \mathrm{SO}_{4}$ measuring $5 \mathrm{mM}$ was employed as the mobile phase with a constant flow rate of $0.5 \mathrm{ml} / \mathrm{min}$. Data analysis was performed using the Waters e2695 separation module.

\section{Transformation of Myceliophthora Protoplasts}

Polyethylene glycol-mediated transformation of $M$. thermophila protoplasts was performed as described previously (Liu et al.,
2017). For gene overexpression, $10 \mu \mathrm{g}$ of linearized plasmid was co-transformed into $M$. thermophila protoplasts, and an antibody was employed for transformant selection on a plate as needed. The putative transformants were selected with antibodies and followed by sequential identification via PCR with paired primers (Supplementary Table S1).

\section{Malonate-Production Medium}

Shaken-flask cultivation was performed with $50 \mathrm{ml}$ of medium inoculated with mature spores at a final concentration of $2.5 \times 10^{5}$ spores $/ \mathrm{ml}$ in $250-\mathrm{ml}$ Erlenmeyer flasks. The culture was incubated at $45^{\circ} \mathrm{C}$ with shaking at $150 \mathrm{rpm}$, and the sample $(1 \mathrm{ml})$ was taken at different intervals. Each liter of the cultivation medium contained $20 \mathrm{~g}$ of glucose, $0.15 \mathrm{~g}$ of $\mathrm{KH}_{2} \mathrm{PO}_{4}, 0.15 \mathrm{~g}$ of $\mathrm{K}_{2} \mathrm{HPO}_{4}, 0.1 \mathrm{~g}$ of $\mathrm{MgSO}_{4} \cdot 7 \mathrm{H}_{2} \mathrm{O}, 0.1 \mathrm{~g}$ of $\mathrm{CaCl}_{2} \cdot 2 \mathrm{H}_{2} \mathrm{O}, 8 \mathrm{~g}$ of Bacto peptone, $1 \mathrm{ml}$ of biotin $(0.1 \mathrm{~g} / \mathrm{L})$, and $1 \mathrm{ml}$ of trace elements of Vogel's salt and was sterilized by autoclaving. Subsequently, sterilized $\mathrm{CaCO}_{3}$ was used as a neutralizing agent at a final concentration of $20 \mathrm{~g} / \mathrm{L}$ to keep the $\mathrm{pH}$ at approximately 6.0.

\section{RESULTS AND DISCUSSION}

\section{Design of an Artificial Biosynthetic Pathway of Malonic Acid}

A novel artificial biosynthetic route was devised to produce malonic acid with OAA as the substrate. In this route, OAA is converted to MSA by a-keto decarboxylase (Kdc) and then to malonic acid (Figure 1A). Kdc is the crucial enzyme step required to divert flux from OAA to malonic acid, which is widespread in plants, yeasts, and fungi. Kdc has been widely used in the non-native synthetic pathway of biofuels, in which Kdc converted 2-keto acids from amino acid biosynthesis pathways to aldehyde and then catalyzed by dehydrogenase to produce alcohols, including 1propanol, 1-butanol, and isobutanol (Atsumi et al., 2008). Substantial numbers of Kdc have been identified and characterized. Moreover, the protein engineering and method of high-throughput screening have been developed to improve the thermostability, substrate specificity, and activity of Kdc. Therefore, it was possible to find a Kdc to catalyze OAA to MSA. In addition, another key enzyme MSA dehydrogenase has been screened, and succinate semialdehyde dehydrogenase encoded by yneI from $E$. coli has been used for catalyzing MSA to malonic acid (Fuhrer et al., 2007; Sullivan and Holyoak, 2007; Zheng et al., 2013; Song et al., 2016). Therefore, the novel pathway for synthesizing malonic acid was theoretically feasible.

In microbes, OAA is the intermediate of the cytoplasmic reductive tricarboxylic acid (rTCA) pathway and mitochondrial TCA cycle. Assuming that glucose is channeled to OAA via the glycolysis pathway and rTCA pathway in turn, $1 \mathrm{~mol}$ of glucose produces $2 \mathrm{~mol}$ of $\mathrm{OAA}$ and $2 \mathrm{~mol}$ of $\mathrm{NADH}$, accompanied by fixation of $2 \mathrm{~mol}$ of $\mathrm{CO}_{2}$ via carboxylation of pyruvate catalyzed by pyruvate carboxylase. The formed $2 \mathrm{~mol}$ of OAA can be converted to $2 \mathrm{~mol}$ of malonic acid and $2 \mathrm{~mol}$ of NADH. In total, $1 \mathrm{~mol}$ of glucose produces 2 mol of malonic acid and $4 \mathrm{~mol}$ of $\mathrm{NADH}$, by which it achieves the theoretical maximum yield of $2 \mathrm{~mol} / \mathrm{mol}$ of glucose (Figure 1B). The 


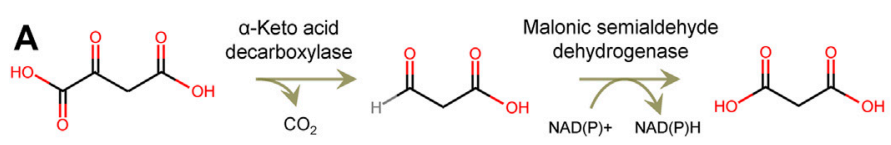

Oxaloacetic acid

Malonic semialdehyde

Malonic acid

B

\begin{tabular}{|c|c|}
\hline Glycolytic pathway & 1 Glucose $+2 \mathrm{ADP}+2 \mathrm{NAD}^{+} \longrightarrow 2$ Pyruvate $+2 \mathrm{ATP}+2 \mathrm{NADH}$ \\
\hline $\begin{array}{c}\text { Reductive TCA } \\
\text { pathway }\end{array}$ & 2 Pyruvate +2 ATP $+\mathrm{CO}_{2} \longrightarrow 2$ Oxaloacetic acid +2 ADP \\
\hline $\begin{array}{l}\text { Synthentic pathway of } \\
\text { malonic acid }\end{array}$ & 2 Oxaloacetic acid $+2 \mathrm{NAD}^{+} \longrightarrow 2$ Malonic acid $+2 \mathrm{CO}_{2}+2 \mathrm{NADH}$ \\
\hline Total & 1 Glucose $+4 \mathrm{NAD}^{+} \longrightarrow 2$ Malonic acid + 4 NADH \\
\hline
\end{tabular}

FIGURE 1 | The artificial synthetic pathway of malonic acid. (A) Oxaloacetic acid is converted to malonic semialdehyde by a-keto decarboxylase and then malonic acid by malonic semialdehyde dehydrogenase. (B) The theoretical maximum yield of malonic acid from glucose.

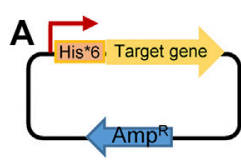

1. Synthesis of His label a-keto decarboxylase<smiles>[131IH]</smiles>

\section{Transformed into} E. coli BL21(DE3)
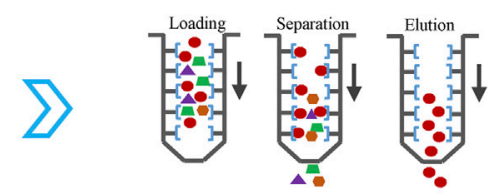

3. IPTG induction and purified enzyme solution

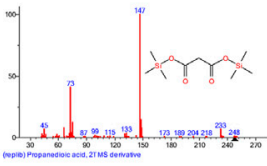

5. GS-MS detection
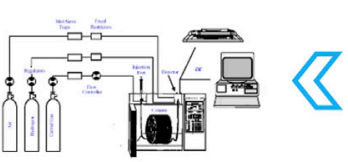

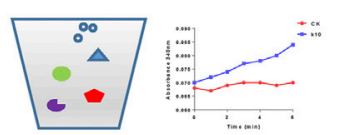

4. Enzyme and substrate reaction at $37^{\circ} \mathrm{C}$, detecting $\mathrm{NADH}$ generation at $340 \mathrm{~nm}$
B

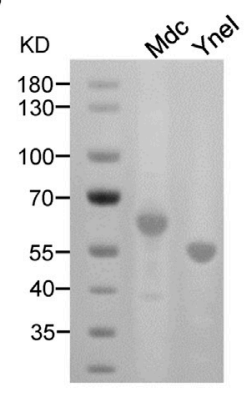

C

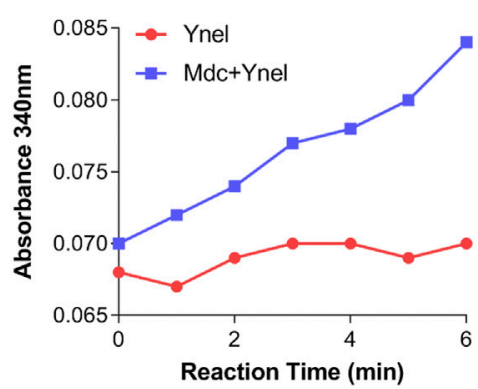

D

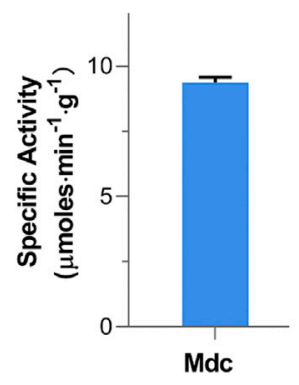

FIGURE 2 | The screening of Kdc using multi-enzyme system in vitro. (A) Summary of screening a-keto decarboxylase. (B) Sodium dodecyl sulfate-polyacrylamide gel electrophoresis (SDS-PAGE) of purified Mdc (oxaloacetate decarboxylase) and Ynel (malonic semialdehyde dehydrogenase). Lane M, molecular weight marker; Lane 1, elution fraction containing purified Mdc (predicted molecular mass of the monomer, $62.9 \mathrm{kDa}$ ); and Lane 2, elution fraction containing purified Ynel (predicted molecular mass of the monomer, $50 \mathrm{kDa}$ ). (C) Time course of absorbance increase of $\mathrm{NADH}$-coupled assay at $340 \mathrm{~nm}$. Red: the reaction mixture only containing Ynel. Blue: the reaction mixture containing Mdc and Ynel. (D) Specific activity of purified single Mdc. 

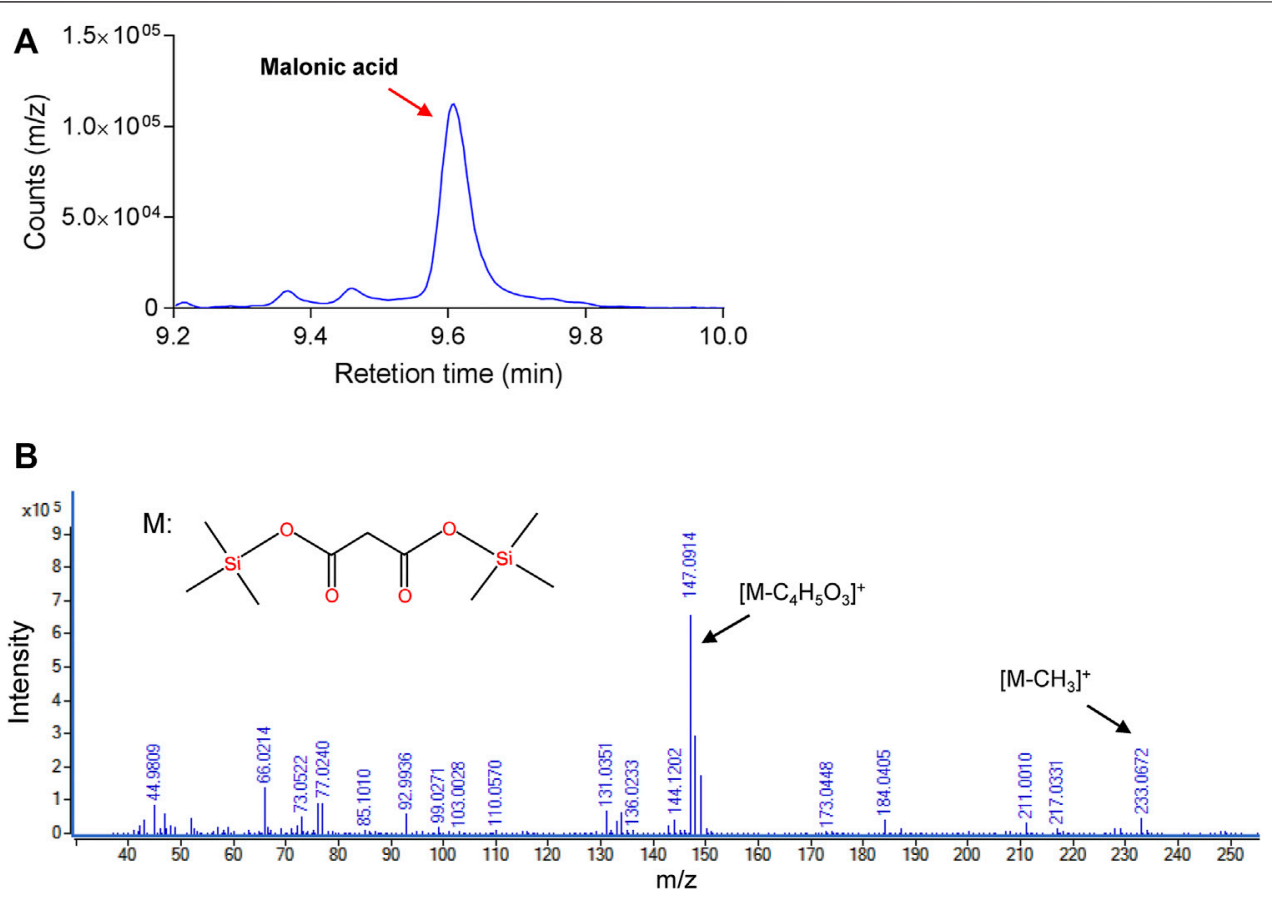

FIGURE 3 | Identification of malonic acid in multi-enzyme reaction by gas chromatography/mass spectrometry (GC/MS). (A) GC assay of malonic acid in enzyme reaction in vitro. (B) MS spectra for synthesized malonic acid.

net NADH can be used for the synthesis of cell compounds and energy metabolites.

\section{Synthesis of Malonic Acid by Artificial Synthetic Route In Vitro}

TPP-dependent keto decarboxylase (Kdc) is a critical enzyme in malonic acid production, and some members have been used for the production of keto acid-derived alcohols (Iding et al., 1998). During the reaction of decarboxylation of OAA, $\beta$-carboxylate is easier to be replaced by hydrogen atom than $a$-carboxylate, which might result in difficulty of mining the highly active enzyme (Sullivan and Holyoak, 2007). To test the capability of using OAA as a substrate, five Kdc candidates, including Thi3, Aro10 from S. cerevisiae (Vuralhan et al., 2003), Pdc from Clostridium acetobutylicum (Iding et al., 1998), Kivd from Lactococcus lactis (Plaza et al., 2004), and Mdc from $O$. parapolymorpha, together with succinate semialdehyde dehydrogenase-encoding YneI from E. coli, were heterologously overexpressed in E. coli BL21 (DE3) as an N-terminal His ${ }^{\star} 6-$ tagged protein. After induction of protein expression, the target proteins were purified and characterized. The NADH-coupled enzyme assay was chosen for the characterization of these purified Kdc enzymes (Figures 2A,B). As shown in Figure 2C, the only reaction mixture containing $\mathrm{Mdc}$ and excessive YneI exhibited increased absorbance at $340 \mathrm{~nm}$. GC/MS analysis further revealed that purified Mdc and YneI catalyzed OAA to produce malonic acid (Figure 3), and the concentration of malonic acid was up to $8.1 \mathrm{mg} / \mathrm{L}$. These data indicated that Mdc had the ability to catalyze OAA to MSA and the specific activity achieved $9.37 \mu \mathrm{mol} / \mathrm{min} / \mathrm{g}$ (Figure 2D). In vitro multi-enzyme system has emerged as a promising bio- manufacturing platform for producing desired products (Sun et al., 2019). The artificial biosynthetic pathway, including only two enzymes, may be feasible to produce malonic acid in vitro in the future.

In order to obtain oxaloacetate decarboxylase with high activity, 40 orthologs of $\mathrm{Mdc}$ were further chosen from the National Center for Biotechnology Information (NCBI) database by protein Blast with the protein sequence of $\mathrm{Mdc}$ as the query and tested for its activity of oxaloacetate decarboxylase (Supplementary Table S2). Disappointingly, none of these 40 members possessed the ability to catalyze OAA to MSA.

\section{The Artificial Malonate Biosynthetic Pathway Can Function in Myceliophthora thermophila}

Thermophilic fungus $M$. thermophila has been engineered to produce C4-dicarboxylic acids, malic acid, and fumaric acid, by cytoplasmic rTCA pathway (Gu et al., 2018; Li et al., 2020a), which can provide precursor OAA for producing malonic acid. Therefore, in order to test whether this artificial malonic pathway can function in vivo, both $m d c$ and $y n e I$ were integrated into the genome of $M$. thermophila wild-type strain, under the control of the strong constitutive promoters of ap (transcriptional enhancer factor) and $p g k$, respectively (Figure 4A). After confirmation via PCR analysis, the engineered strains were tested for the production of malonic acid with glucose as the carbon source. Malonic acid in the culture of the strain of SG214 was detected by GC/MS assay, and the titer achieved $40.8 \mathrm{mg} / \mathrm{L}$ (Figure 4B), indicating that the artificial malonate synthetic pathway we designed can work functionally in vivo. It 

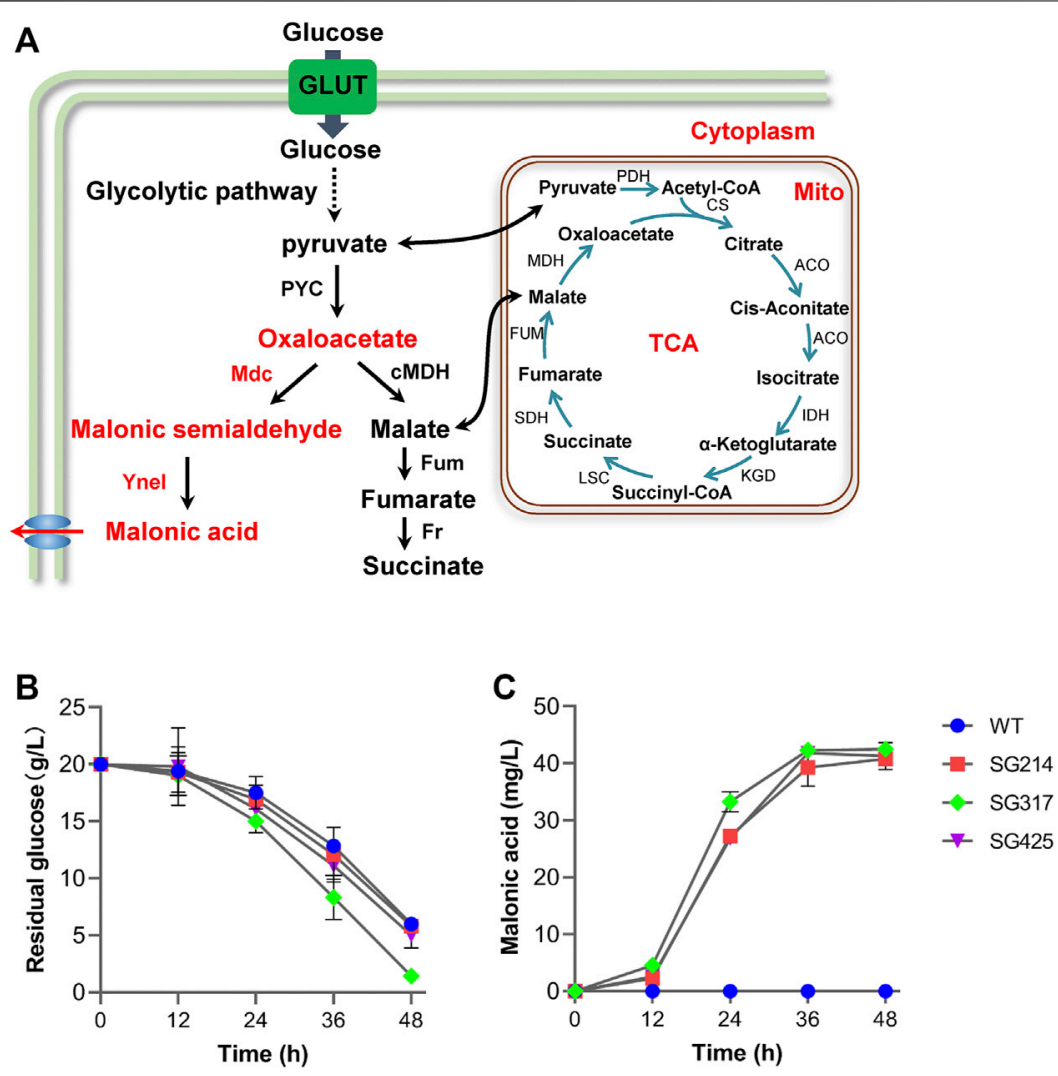

FIGURE 4 | Introduction of malonic acid synthesis pathway in Myceliophthora thermophila. (A) Overall scheme of malonic acid synthesis in M. thermophila. Time course of glucose consumption (B) and malonic acid production (C) by M. thermophila mutants grown on glucose medium. WT, M. thermophila wild-type strain; strain SG214 containing mdc and ynel; Strain SG317 containing mdc, ynel, and glt-1; Strain SG425 containing mdc, ynel, and Anmae1; PEP, phosphoenolpyruvate; GLUT, glucose transporter; PYC, pyruvate carboxylase; CMDH, cytoplasm malate dehydrogenase; Fum, fumarase; Fr, fumarate reductase; TCA, tricarboxylic acid cycle; $\mathrm{PDH}$, pyruvate dehydrogenase; CS, citrate synthase; ACO, aconitase; IDH, isocitrate dehydrogenase; KGD, a-ketoglutarate dehydrogenase complex; LSC, succinyl$\mathrm{COA}$ synthetase; $\mathrm{SDH}$, succinate dehydrogenase; $\mathrm{MDH}$, mitochondrial malate dehydrogenase.

presented a promising approach to produce malonic acid direct from renewable plant cell biomass in this cellulolytic thermophilic fungus in the future.

\section{No Obvious Improvement was Obtained by Overexpression of Glucose Transporter and a Predicted Exporter of Malonic Acid}

Rapid substrate supply was recognized as one strategy to maintain a high flux of reaction, which is a prerequisite for efficient cell factory production of biochemicals. Glucose transporter gene glt-1 from $N$. crassa has been systematically characterized and used for improving the production of commodity chemicals, such as malic acid and ethanol (Chen et al., 2017; Wang et al., 2017; Li et al., 2020b). Therefore, to improve the malonic acid production, gene glt- 1 was incorporated into the $M$. thermophila SG214 strain, under the strong constitutive promoter of gpdA (MYCTH_2311855). After confirmation of the presence of the transgene by PCR analysis, the production of malonic acid by resultant strain SG317 was assayed. As shown in Figures 4B,C, the introduction of glt-1 enabled faster glucose utilization and malonate production, while titer of malonic acid ( $42.5 \mathrm{mg} / \mathrm{L})$ exhibited a slight increase compared with the parental strain SG214 (Figure 4B). These data suggested that glucose absorbability is not the key bottleneck for the current version of the cell factory, and other strategies are needed to increase the production of malonic acid.

Previous research on metabolic engineering of chemical products showed that effective export of target products is the key factor of efficient production of desirable products, and overexpression of exporters leads to the improved synthesis of organic acids, such as malic and fumaric acid (Chen et al., 2017). It was reported previously that Anmae1, a C4-dicarboxylate transporter from $A$. niger, has the capability to export malonic acid, and it has been introduced into $P$. kudriavzevii for increased malonate production (Dietrich et al., 2017). Disappointingly, when the gene Anmael was overexpressed in the strain of SG214, under the control of the constitutive promoter of $p g k$ (MYCTH_2316240), malonic acid production $(41.3 \mathrm{mg} / \mathrm{L})$ and glucose consumption rate by the resultant strain SG425 showed no significant increase, compared with the parent strain.

In order to improve the performance of cell factories for malonic acid production, more strategies of metabolic modification would be needed in the future, such as improvement of activity of key enzymes, disruption of branch points of the synthetic pathway, and enhancement of precursor pool size. In addition, intracellular high 
concentrations of malonate can competitively inhibit succinate dehydrogenase activity, which would lead to metabolic disturbance of host cells. Increasing host cell tolerance to malonate may be another strategy for the efficient production of malonic acid.

\section{CONCLUSION}

In this study, we designed a novel artificial pathway for malonic acid biosynthesis with OAA as the substrate. The pathway was first tested in vitro. OAA can be converted to MSA by a-keto decarboxylase (Mdc) and then to malonic acid by the second enzyme (YneI). Then, using a cellulolytic fungus $M$. thermophila as the host, this novel pathway was functionally constructed in vivo. The present study provides a new potential option to produce malonic acid from glucose and even plant biomass in the future.

\section{DATA AVAILABILITY STATEMENT}

The original contributions presented in the study are included in the article/Supplementary Material, further inquiries can be directed to the corresponding authors.

\section{REFERENCES}

Atsumi, S., Hanai, T., and Liao, J. C. (2008). Non-fermentative Pathways for Synthesis of Branched-Chain Higher Alcohols as Biofuels. Nature 451 (7174), 86-89. doi:10.1038/nature06450

Berka, R. M., Grigoriev, I. V., Otillar, R., Salamov, A., Grimwood, J., Reid, I., et al. (2011). Comparative Genomic Analysis of the Thermophilic BiomassDegrading Fungi Myceliophthora Thermophila and Thielavia Terrestris. Nat. Biotechnol. 29 (10), 922-927. doi:10.1038/nbt.1976

Chae, T. U., Ahn, J. H., Ko, Y.-S., Kim, J. W., Lee, J. A., Lee, E. H., et al. (2020). Metabolic Engineering for the Production of Dicarboxylic Acids and Diamines. Metab. Eng. 58, 2-16. doi:10.1016/j.ymben.2019.03.005

Chen, X., Wang, Y., Dong, X., Hu, G., and Liu, L. (2017). Engineering rTCA Pathway and C4-Dicarboxylate Transporter for L-Malic Acid Production. Appl. Microbiol. Biotechnol. 101 (10), 4041-4052. doi:10.1007/s00253-017-8141-8

Dave, K. K., and Punekar, N. S. (2015). Expression of Lactate Dehydrogenase in Aspergillus niger for L-Lactic Acid Production. PLoS One 10 (12), e0145459. doi:10.1371/journal.pone.0145459

Dietrich, J. A., Fortman, J. L., and Steen, E. J. (2017). Recombinant Host Cells for the Production of Malonate. US patent WO 2013/134424 A1. San Francisco (US).

Fuhrer, T., Chen, L., Sauer, U., and Vitkup, D. (2007). Computational Prediction and Experimental Verification of the Gene Encoding the NAD +/NADP + -Dependent Succinate Semialdehyde Dehydrogenase in Escherichia coli. J. Bacteriol. 189 (22), 8073-8078. doi:10.1128/JB.01027-07

Gu, S., Li, J., Chen, B., Sun, T., Liu, Q., Xiao, D., et al. (2018). Metabolic Engineering of the Thermophilic Filamentous Fungus Myceliophthora Thermophila to Produce Fumaric Acid. Biotechnol. Biofuels 11, 323. doi:10.1186/s13068-0181319-1

Hildbrand, S., and Pollak, P. (2012). Malonic Acid and Derivatives. Ullmann's Encyclopedia Ind. Chem., 157-174. doi:10.1002/14356007.a16_063.pub2

Iding, H., Siegert, P., Mesch, K., and Pohl, M. (1998). Application of $\alpha$-keto Acid Decarboxylases in Biotransformations. Biochim. Biophys. Acta (Bba) - Protein Struct. Mol. Enzymol. 1385 (2), 307-322. doi:10.1016/s01674838(98)00076-4

Kirimura, K., Kobayashi, K., Ueda, Y., and Hattori, T. (2016). Phenotypes of Gene Disruptants in Relation to a Putative Mitochondrial Malate-Citrate Shuttle Protein in Citric Acid-Producing Aspergillus niger. Biosci. Biotechnol. Biochem. 80 (9), 1737-1746. doi:10.1080/09168451.2016.1164583

\section{AUTHOR CONTRIBUTIONS}

CT and JL designed the experiments. SG, ZZ, YY, and JL performed the metabolic engineering experiments and analyze the data. CT, JL, and SG wrote the manuscript. All authors read and approved the final manuscript.

\section{FUNDING}

This work was supported by funding from the Key Project of the Ministry of Science and Technology of China (2018YFA0900500 and 2018YFA0901400), the Chinese Academy of Sciences (XDA21060900), and the Youth Innovation Promotion Association of the Chinese Academy of Sciences (2020183).

\section{SUPPLEMENTARY MATERIAL}

The Supplementary Material for this article can be found online at: https://www.frontiersin.org/articles/10.3389/fbioe.2021.820507/ full\#supplementary-material

Klikar, M., Jelínková, V., Růžičková, Z., Mikysek, T., Pytela, O., Ludwig, M., et al. (2017). Malonic Acid Derivatives on Duty as Electron-Withdrawing Units in Push-Pull Molecules. Eur. J. Org. Chem. 2017 (19), 2764-2779. doi:10.1002/ ejoc. 201700070

Li, J., Lin, L., Sun, T., Xu, J., Ji, J., Liu, Q., et al. (2020a). Direct Production of Commodity Chemicals from Lignocellulose Using Myceliophthora Thermophila. Metab. Eng. 61, 416-426. doi:10.1016/j.ymben.2019.05.007

Li, J., Zhang, Y., Li, J., Sun, T., and Tian, C. (2020b). Metabolic Engineering of the Cellulolytic Thermophilic Fungus Myceliophthora Thermophila to Produce Ethanol from Cellobiose. Biotechnol. Biofuels 13, 23. doi:10.1186/s13068-020-1661-y

Liu, Q., Gao, R., Li, J., Lin, L., Zhao, J., Sun, W., et al. (2017). Development of a Genome-Editing CRISPR/Cas9 System in Thermophilic Fungal Myceliophthora Species and its Application to Hyper-Cellulase Production Strain Engineering. Biotechnol. Biofuels 10, 1. doi:10.1186/s13068-016-0693-9

Mao, Y., Yuan, Q., Yang, X., Liu, P., Cheng, Y., Luo, J., et al. (2021). Non-natural Aldol Reactions Enable the Design and Construction of Novel One-Carbon Assimilation Pathways In Vitro. Front. Microbiol. 12, 677596. doi:10.3389/ fmicb.2021.677596

Plaza, M., Fernández de Palencia, P., Pelã $j e z$, C., and Requena, T. (2004). Biochemical and Molecular Characterization of $\hat{\mathrm{I}} \pm$-Ketoisovalerate Decarboxylase, an Enzyme Involved in the Formation of Aldehydes from Amino Acids byLactococcus Lactis. FEMS Microbiol. Lett. 238 (2), 367-374. doi:10.1016/j.femsle.2004.07.057

Singh, B. (2016). Myceliophthora thermophilasyn.Sporotrichum Thermophile: a Thermophilic Mould of Biotechnological Potential. Crit. Rev. Biotechnol. 36 (1), 59-69. doi:10.3109/07388551.2014.923985

Song, C. W., Kim, J. W., Cho, I. J., and Lee, S. Y. (2016). Metabolic Engineering of Escherichia coli for the Production of 3-Hydroxypropionic Acid and Malonic Acid through $\beta$-Alanine Route. ACS Synth. Biol. 5 (11), 1256-1263. doi:10.1021/acssynbio.6b00007

Sullivan, S. M., and Holyoak, T. (2007). Structures of Rat Cytosolic PEPCK: Insight into the Mechanism of Phosphorylation and Decarboxylation of Oxaloacetic Acid,. Biochemistry 46, 10078-10088. doi:10.1021/bi701038x

Sun, S., Wei, X., and You, C. (2019). The Construction of an In Vitro Synthetic Enzymatic Biosystem that Facilitates Laminaribiose Biosynthesis from Maltodextrin and Glucose. Biotechnol. J. 14 (4), 1800493. doi:10.1002/biot.201800493

Vuralhan, Z., Morais, M. A., Tai, S.-L., Piper, M. D. W., and Pronk, J. T. (2003). Identification and Characterization of Phenylpyruvate Decarboxylase Genes in Saccharomyces cerevisiae. Appl. Environ. Microbiol. 69 (8), 4534-4541. doi:10.1128/aem.69.8.4534-4541.2003 
Wang, B., Li, J., Gao, J., Cai, P., Han, X., and Tian, C. (2017). Identification and Characterization of the Glucose Dual-Affinity Transport System in Neurospora Crassa: Pleiotropic Roles in Nutrient Transport, Signaling, and Carbon Catabolite Repression. Biotechnol. Biofuels 10, 17. doi:10.1186/s13068-017-0705-4

Werpy, T. A., Holladay, J. E., White, J. F., Bozell, J., Holladay, J., White, J., et al. (2004). Top Value Added Chemicals from Biomass I. Results of Screening for Potential Candidates from Sugars and Synthesis. Washington, D.C. (United States): EERE Publication and Product Library. doi:10.2172/926125

Yang, F., Gong, Y., Liu, G., Zhao, S., and Wang, J. (2015). Enhancing Cellulase Production in Thermophilic Fungus Myceliophthora Thermophila ATCC42464 by RNA Interference of Cre1 Gene Expression. J. Microbiol. Biotechnol. 25 (7), 1101-1107. doi:10.4014/jmb.1501.01049

Zheng, H., Beliavsky, A., Tchigvintsev, A., Brunzelle, J. S., Brown, G., Flick, R., et al. (2013). Structure and Activity of the NAD(P)+-dependent Succinate Semialdehyde Dehydrogenase YneI fromSalmonella Typhimurium. Proteins 81 (6), 1031-1041. doi:10.1002/prot.24227
Conflict of Interest: The authors declare that the research was conducted in the absence of any commercial or financial relationships that could be construed as a potential conflict of interest.

Publisher's Note: All claims expressed in this article are solely those of the authors and do not necessarily represent those of their affiliated organizations, or those of the publisher, the editors, and the reviewers. Any product that may be evaluated in this article, or claim that may be made by its manufacturer, is not guaranteed or endorsed by the publisher.

Copyright (C) 2022 Gu, Zhao, Yao, Li and Tian. This is an open-access article distributed under the terms of the Creative Commons Attribution License (CC BY). The use, distribution or reproduction in other forums is permitted, provided the original author(s) and the copyright owner(s) are credited and that the original publication in this journal is cited, in accordance with accepted academic practice. No use, distribution or reproduction is permitted which does not comply with these terms. 